Journal of Animal and Veterinary Advances 11 (18): 3457-3462, 2012

ISSN: $1680-5593$

(C) Medwell Journals, 2012

\title{
The Benefits of Using Bacillus as a Probiotic
}

\author{
${ }^{1}$ K. Y. Hwang, ${ }^{3}$ J.H. Cho, ${ }^{1}$ J.Y. Lee, ${ }^{1}$ K.D. Kang, ${ }^{1,}{ }^{2}$ S.I. Seong and ${ }^{3}$ I.H. Kim \\ ${ }^{1}$ R\&D Center for Life Science, Biotopia Co., Ltd., \\ Chuncheon, 200-883 Gangwon, Republic of Korea \\ ${ }^{2}$ Department of Life Science, The University of Suwon, Hwaseong, \\ 445-743 Gyeonggi, Republic of Korea \\ ${ }^{3}$ Department of Animal Resource and Science, Dankook University, \\ Cheonan, 330-714 Choognam, Republic of Korea
}

\begin{abstract}
Microorganisms such as lactic acid bacteria, Bacillus sp., Clostridium sp. and E. coli which have been used as animal probiotics for a long time are well suited to their major purpose and are known to be beneficial inside the animal digestive tract. Bacillus probiotics play a significant role in improving the productivity of animals (livestock) by producing various useful metabolites under optimal culture conditions. In addition, they actively contribute to improving the environment of domesticated animals through the promotion of immunity against diseases and improvements in feed efficiency.
\end{abstract}

Key words: Microorganisms, Bacillus, probiotics, animal, environment, feed

\section{INTRODUCTION}

Why is Bacillus highly effective as a probiotic when it has low activity in the small intestine of animals? Types of probiotic microorganisms and their functional characteristics: Various microorganisms can be used as probiotics. Bacteria is one of the most commonly used probiotics which include many species such as Lactobacillus, Streptococcus, Enterococcus, Bacillus, Clostridium, Bifidobacterium, Rhodobacter and E. coli (Kruis et al., 2004). Certain fungal species are also used as probiotics including both yeasts (Saccharomyces sp.) and molds (Aspergillus sp.). Bacterial probiotics are known to be effective in poultry, pigs and calves with undeveloped rumen whereas fungal probiotics are generally effective in ruminants (Fuller, 1999).

Fungi contain many intracellular components such as vitamins and unidentified growth factors. However, fungal cells possess rigid cell walls that are very different from the cell walls of bacteria which cannot be broken down by the digestive enzymes secreted by the gastrointestinal tract in monogastric animals. In contrast, ruminant animals contain various enzyme-producing microbes in their rumens that can digest the cell walls of fungi. Therefore, it is thus more beneficial to use fungal probiotics with ruminants in terms of nutrient supply. Specifically, the molecular structure of the bacterial cell wall is mainly composed of peptidoglycan which is easily digested by the normal intestinal enzymes produced by monogastric animals. The structure of the fungal cell wall, on the other hand is more complex with glucan as the basic structural unit. Therefore, it is difficult for the monogastric animals to utilize the nutrient present in the cytoplasm of fungal cell because of the limitation of glucan-degrading enzyme. Consequently, it is important to select proper probiotic microorganisms according to the type of livestock involved.

Guidelines exist had already standardize the use of probiotics in food or feed and these guidelines for animal feed require the clear identification of all microorganisms used (FAO/WHO, 2002). In addition, the guidelines also require the safety of the microbes and their functional properties both in vitro and in vivo. The current trend for identifying probiotic microorganisms is to perform PCRbased 16S rDNA sequence analysis (Ben Amor et al., 2007). Strain identification allows for the accurate evaluation or tracing of the microorganisms and is important for epidemiology.

Microorganisms such as lactic acid bacteria, Bacillus sp., Clostridium sp. and E. coli which have been used as animal probiotics for a long time are well suited to their major purpose and are known to be beneficial inside the animal digestive tract. The advantages of these microbial probiotics are their similar characteristics to the resident bacteria in the animal digestive tract which allowed them to form clusters in the intestinal mucosa and then

Corresponding Author: Ho Kim, Department of Animal Resource and Science, Dankook University, No. 29 Anseodong, Cheonan, 330-714 Choognam, South Korea 
eliminate harmful bacteria through successful competition for nutrients. Moreover, probiotics could inhibit the production of toxins such as indole, skatole, phenol, amines and ammonia. They also promote the formation of immune system proteins such as $\operatorname{Ig} \mathrm{A}, \operatorname{IgG}$ and $\operatorname{IgM}$ to boost immunity and improve nutrient utilization through the promotion of sugar absorption and enzyme production. Probiotics have also been reported to provide various benefits to animals (Lee, 2008) by producing antimicrobial agents such as bacteriocin, $\mathrm{H}_{2} \mathrm{O}_{2}, \mathrm{CO}_{2}$ and diacetyl as well as low-molecular-weight antibiotics (Parvez et al., 2006).

\section{THE EFFECTIVENESS OF TAKING BACILUS PROBIOTICS}

Probiotic microorganisms need to be examined from a variety of perspectives. Bacterial probiotics other than Bacillus (e.g., the lactic acid bacteria or bifidus) must first be able to reach the digestive tract and then be able to survive and multiply there. Hence, most probiotic microorganisms must have the capacity to resist acid and bile salts (Prasad et al., 1998).

Bacillus however could form resting spores which are not as restricted as other probiotics. Usually, Bacillus only multiplies to a small degree when reaches the small intestine; thereafter, Bacillus multiplies extensively in the large intestine (colon) and is shed in the feces (Casula and Cutting, 2002; Leser et al., 2008). In the past, it was assumed that they passed through the anaerobic gastrointestinal tract as spores when the resting spores of Bacillus were administered orally. Recent reports however indicated that Bacillus can grow as a facultative anaerobe and it is capable of living a sporulation-germinationsporulation life cycle in the gastrointestinal tract (Earl et al., 2008). Studies examining the multiplication of Bacillus spores revealed that proliferation in the small intestine was difficult despite the presence of rich nutrients, a low $\mathrm{pH}$ and many indigenous organic acid producing microorganisms. In contrast, multiplication was improved in the large intestine which has fewer nutrients and a neutral pH (Tam et al., 2006). Additionally, the resting spores present in Bacillus probiotics have been reported to germinate in the small intestine where they act similarly to the probiotics derived from the lactic acid bacteria (Casula and Cutting, 2002). However, Cartman et al. (2008) did not observed any growth in small intestine when the growth of Bacillus spores was examined in the digestive tract of poultry although, the spores multiplied well in the cecum and the colon. The gastrointestinal tract of animals exists in an oxygen-free (anaerobic) state. Furthermore, the indigenous bacteria (e.g., the lactic acid bacteria) present in the intestine create a relatively difficult environment to grow.

Nevertheless, probiotics containing only Bacillus or probiotics complex based on Bacillus, demonstrated great efficacy in animal studies (Hong et al., 2005). In breeding pigs, Bacillus sp. are often used to improve livestock productivity by promoting the growth and meat quality and protect the environment by eliminating the odor of the pig pens and manure (Lee, 2008).

Administering Bacillus-based probiotics to pigs is effective in improving their growth and feeding efficiency while reducing the volatile fatty acids that cause odors (Chen et al., 2006). Studies also suggested that probiotics can improve digestion and reduce the production of those fecal compounds that influence odor such as ammonia, hydrogen sulfide and short chain fatty acids (Chiang and Hsieh, 1995; Otto et al., 2003).

Given these observations, researchers need to consider the reasons why Bacillus appears so many benefits despite the fact that it cannot actively grow in the animal gastrointestinal tract. In summarizing, the basic information available on probiotics, Musa et al. (2009) stated the importance of selecting the appropriate microorganism for particular type of animal and determining the necessary countermeasures for side effects and the results of specification. Furthermore, the researchers further claimed that the various effects produced by probiotics could be attributed to the probiotics themselves or their external culture environment. In other words, probiotic organisms do provide benefits to the animals but even better effects are seen when the animals are orally fed the various fermentation metabolites generated during the cultivation of Bacillus species.

\section{ENZYMES AND METABOLITES PRODUCED BY BACILLUS}

Among the bacteria used as probiotics, Bacillus is best known for its ability to produce various digestive enzymes including amylase (starch digestion), protease (protein digestion), phosphatase (phosphoric acid degradation); phytase, glucanase, isomerase and fiberdigesting enzymes (Priest, 1977). However, the level of enzyme produced is low during the process of Submerged Fermentation (SMF) which is used to produce probiotics rather than to stimulate enzyme production. Thus, feeding animals with probiotics produced in this manner may improve the digestibility of the feed but the effect of the enzymes alone is unlikely to improve the overall productivity of the animals.

Bacillus probiotics also produce many types of amino acids, nucleic acids, peptides, oligomers and 
biosurfactants when they are cultured as a production medium for grain-based ingredients such as soybeans and rice bran. Therefore, additional effects are expected from the Bacillus-produced enzymes beyond the simple promotion of digestibility.

\section{ADDITIONAL EFFECTS DUE TO MORPHOLOGICAL CHANGES IN BACILLUS}

Unlike other non-spore forming bacterial probiotics, Bacillus has a unique life cycle that produces resting endospores. During endospore formation, the morphology of the bacterial cell changes according to changes in the surrounding growth environment. As shown in Fig. 1, Bacillus produces primary metabolites during the heat-sensitive vegetative cell stage by repetitive cycles of growth and multiplication. As incubation time increases, the surrounding environment deteriorates because of the declining availability of nutrients necessary for the production of primary metabolites and the proliferation of vegetative cells becomes more difficult. Morphological changes begin to occur at this time and Bacillus shifts to the production of secondary metabolites. Eventually, the resting endospore which is strongly resistant to heat and poor environmental conditions is completely formed and the mother cell is hydrolyzed (Demain, 1980).

Bacillus sp. that perform secondary metabolism are often compared to the actinomycetes which also form spores show similar morphological changes and produce various secondary metabolites prior to spore formation in the case of strains capable of morphological change. The secondary metabolites produced during this process include various antimicrobial materials such as broadspectrum antibiotics, ergot alkaloids, naphthalene, nucleosides, peptides, phenazine, quinolone, terpenoids and several types of complex growth factors (Martin and Demain, 1980). In addition, Bacillus produces biosurfactants as a secondary metabolite. Most of these biosurfactants contribute significantly to the increased productivity of the livestock because of its broadspectrum antimicrobial activity. Besides, biosurfactants could also aid emulsification and micelle formation to promote the absorption of insoluble compounds, including some feed nutrients and certain types of drugs.

Furthermore as shown in Fig. 1, after completing endospore formation of Bacillus sp., the spore is released as a free spore while the cell wall peptidoglycan of the mother cell is degraded by autolysin. Meanwhile, the intracellular components of the organism such as the cytoplasm, cell membrane and cell wall are released to the extracellular medium (Smith and Foster, 1995;

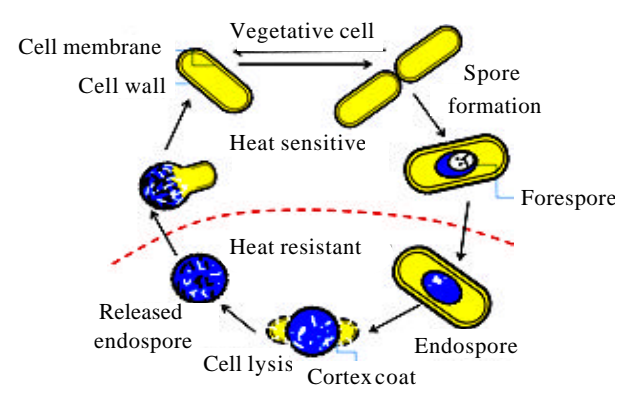

Fig. 1: Diagram of the morphological life cycle of Bacillus

Hosoya et al., 2007) which can also be used to improve livestock productivity. Therefore, researchers suggested that the endospore formation will not only provide nutrients but also increase the ability to absorb feed compounds because of the absorption-promotion effects of biosurfactants such as glycolipids and phospholipids.

\section{SECONDARY METABOLITES PRODUCED BY BACILLUS}

Approximately 167 different types of antibiotics have been detected in Bacillus with 66 agents produced by B. subtilis and 23 agents produced by $B$. brevis (Awais et al., 2010). In addition to antibiotics, numerous insecticides, nucleotides, nucleosides (Demain, 1987) and amino acids (Priest, 1989) are also produced by different strains of Bacillus. The Bt toxin produced by Bacillus thuringiensis is one of the best-known Bacillus-derived insecticides and is broadly used in controlling pest species among the dipteran, coleopteran and lepidopteran insects (Whalon and Wingerd, 2003). Additional studies are also being conducted on pests such as moths, mosquitoes and flies to provide assistance in improving the environment of livestock (Copping and Menn, 2000). Moreover, nucleotides also show a variety of effects such as enhancing immune cells in young animals, improving the length of the villi and reducing diarrhea (Martinez-Puig et al., 2005, 2007).

In general, dietary fats do not dissolve in water. Emulsification resulting from the detergent action of bile salts in the intestine allows for the hydrolysis of fats into fatty acids, monoglycerides and diglycerides through the action of lipase.

Fats and their degradation products then form micelles that are absorbed by the intestine. Currently, biosurfactants such as phospholipids, lecithins and lysolecithins are necessary to facilitate this process (Polin, 1980; Soares and Lopez-Bote, 2002). As mentioned before, microorganisms produce many different biosurfactants including glycolipids, lipopeptides, 
phospholipids, surface-active antibiotics, fatty acids/neutral lipids and polymeric surfactants, all of which are derived from cellular components. Bacillus is known to produce such biosurfactants such as surfactin, iturin and fengycin, derived from $B$. subtilis and lichenysin, derived from B. licheniformis (Muthuswamy et al., 2008). Surfactin which is a powerful lipopeptide biosurfactant is a secondary metabolite generated during spore formation and the morphological differentiation of the Bacillus cells (Nakano et al., 1988). Overall, Bacillus-derived metabolites such as biosurfactants can be expected to provide more useful effects than the probiotic spores themselves in terms of animal weight gain, improved feed efficiency, enhanced immunity, disease resistance and improved livestock environment.

\section{PROMOTION OF GROWTH IN ANIMALS BY BACILLUS METABOLITES}

The productivity of livestock has been shown to improve substantially when Bacillus probiotics are given. This benefit occurs despite the fact that Bacillus does not actively grow inside the gastrointestinal tract of animals. The activity of Bacillus-produced enzymes is also low compared with that of normal enzymes. It has been demonstrated that the beneficial effect of Bacillus could be attributed more to the greater influence of its metabolites than its spores.

Lactobacillus helveticus (Narva et al., 2004) is one of the lactic acid bacteria that grow inside the animal gastrointestinal tract. It produces a variety of antibiotics (Thompson et al., 2008) inhibits the attachment of enteropathogenic bacteria to the intestinal mucosa (Sherman et al., 2005; Johnson-Henry et al., 2007) and promotes intestinal calcium absorption to enhance bone mineral density and content. When the oral administration of $L$. helveticus was compared with the oral administration of $B$. subtilis MORI (one of the Bacillus strains used in feed and food products) in animals, the Bacillus group demonstrated greater benefits in terms of feed intake, weight gain, serum IGF levels, iliac length and iliac weight than the group receiving the lactic acid bacteria. Moreover, when the fermentation metabolites produced by $B$. subtilis was orally administered at $200 \mathrm{mg} \mathrm{kg}^{-1}(\mathrm{w} / \mathrm{w})$ along with the insoluble Tetracycline (TC) the group receiving Bacillus fermentation metabolites had significantly higher serum levels of TC after $2 \mathrm{~h}$ than the group receiving TC alone ( $42.3 \pm 4.0$ and $26.3 \pm 0.9 \mu \mathrm{g} \mathrm{mL}^{-1}$, respectively) (Lee et al., 2008). This result demonstrated that fermentation metabolites can promote the absorption of $\mathrm{TC}$ and indirectly suggested that the absorption of partially insoluble feed nutrients can also be improved.
To summarize, Bacillus first uses nutrients derived from its culture media for growth and the production of various primary metabolites. As the incubation time increases, changes in the culture environment such as the depletion of nutrients, drives the organism to transition to the endospore-formation stage. Secondary metabolites are then produced and secreted outside of the cells or cells are hydrolyzed to release beneficial materials into the culture medium. Empirically, the productivity of livestock was greatly enhanced when probiotics containing bacteria and their metabolic products (primary metabolites, secondary metabolites and hydrolyzed cellular materials) were given to the animals than the probiotics containing bacteria only. Among the secondary metabolites produced by Bacillus, biosurfactants not only possess powerful antibacterial capabilities (Jenny et al., 1993) but also facilitate the absorption of beneficial substances in the animal digestive tract. Moreover, alkaloid components produced by Bacillus such as 1-deoxynojirimycin have also been reported to possess antiviral activity (Watson et al., 2001). Altogether, the metabolites produced by Bacillus can contribute to livestock productivity in many ways through their various effects on physiological activity.

\section{CONCLUSION}

Bacillus probiotics play a significant role in improving the productivity of animals (livestock) by producing various useful metabolites under optimal culture conditions. In addition, they actively contribute to improving the environment of domesticated animals through the promotion of immunity against diseases and improvements in feed efficiency.

\section{REFERENCES}

Awais, M., A. Pervez, A. Yaqub and M.M. Shah, 2010. Production of antimicrobial metabolites by Bacillus subtilis immobilized in polyacrylamide gel. Pak. J. Zool., 42: 267-275.

Ben Amor, K., E.E. Vaughan and W.M. DeVos, 2007. Advanced molecular tools for the identification of lactic acid bacteria. J. Nutr., 137: 741 S-747S.

Cartman, S.T., R.M. La Ragione and M.J. Woodward, 2008. Bacillus subtilis spore germinate in the chicken gastrointestinal tract. Applied Environ. Microbiol., 74: 5254-5258.

Casula, G. and S.M. Cutting, 2002. Bacillus probiotics: Spore germination in the gastrointestinal tract. Applied Environ. Microbiol., 68: 2344-2352. 
Chen, Y.J., B.J. Min, J.H. Cho, O.S. Kwon, K.S. Son, H.J. Kim and I.H. Kim, 2006. Effects of dietary Bacillus-based probiotic on growth performance, nutrient digestibility, blood characteristics and fecal noxious gas content in finishing pigs. Asian-Aust. J. Anim. Sci., 19: 587-592.

Chiang, S.H. and W.H. Hsieh, 1995. Effect of direct-fed microorganisms on broiler growth performance and litter ammonia level. Aust. J. Anim. Sci., 8: 159-162.

Copping, L.G. and J.J. Menn, 2000. Biopesticides: A review of their action, applications and efficacy. Pest Manage. Sci., 56: 651-676.

Demain, A.L., 1980. Microbial production of primary metabolites. Naturwissenschaften, 67: 582-587.

Demain, A.L., 1987. Production of nucleotides by microorganism. Econ. Microbiol., 2: 178-208.

Earl, A.M., R. Losick and R. Kolter, 2008. Ecology and genomics of Bacillus subtilis. Trends Microbiol., 16: $269-275$.

FAO/WHO, 2002. Joint FAO/WHO (Food and Agriculture Organization/World Health Organization) working group report on drafting guidelines for the evaluation of probiotics in food. London, Ontario, pp: 1-11.

Fuller, R., 1999. Probiotics for Farm Animals. In: Probiotics: A Critical Review, Tannock, G.W. (Ed.). Horizon Scientific Press, New York, pp: 15-22.

Hong, H.A., H. Duc le and S.M. Cutting, 2005. The use of bacterial spore formers as probiotics. FEMS Microbiol. Rev., 29: 813-835.

Hosoya, S., Z. Lu, Y. Ozaki, M. Takeuchi and T. Sato, 2007. Cytological analysis of the mother cell death process during sporulation in Bacillus subtilis. J. Bacteriol., 189: 2561-2565.

Jenny, K., V. Deltrieu and O. Kappelli, 1993. Lipopeptide Production by Bacillus Licheniformis. In: Biosurfactants: Production, Properties, Applications. Kosaric, N. (Ed.). Marcel Dekker, New York, ISBN: 9780824788117 , Pages: 483.

Johnson-Henry, K.C., K.E. Hagen, M. Gordonpour, T.A. Tompkins and P.M. Sherman, 2007. Surfacelayer protein extracts from Lactobacillus helveticus inhibit enterohaemorrhagic Escherichia coli O157:H7 adhesion to epithelial cells. Cell Microbiol., 9: 356-367.

Kruis, W., P. Fric, J. Pokrotnieks, M. Lukas and B. Fixa et al., 2004. Maintaining remission of ulcerative colitis with the probiotic $E$. col $i$ Nissle 1917 is as effective as with standard mesalazine. Gut, 53: 1617-1623.

Lee, E.Y., 2008. Problems and verification system of probiotics as livestock-environmnet improving agent produced and circulated. Korean J. Microbiol. Biotechnol., 36: 87-95.
Lee, J.Y., Y.S. Park, Y.H. Kim, K.H. Oh and K.Y. Hwang et al., 2008. Effect of new calcium supplementary food containing fermented product of Bacillus on the longitudinal bone growth in the adolescent male rats. J. Korean Soc. Food Sci. Nutr., 37: 1576-1582.

Leser, T.D., A. Knarreborg and J. Worm, 2008. Germination and outgrowth of Bacillus subtilis and Bacillus licheniformis spores in the gastrointestinal tract of pigs. J. Applied Microbiol., 104: 1025-1033.

Martin, J.F. and A.L. Demain, 1980. Control of antibiotic biosynthesis. Microbiol. Rev., 44: 230-251.

Martinez-Puig, D., E. Borda, E.G. Manzanilla, C. Chetrit and J.F. Perez, 2005. Dietary nucleotides supplementation alleviates villous atrophy and improves immune response of early weaned piglets. J. Anim. Sci., 83: 30-30.

Martinez-Puig, D., E.G. Manzanilla, J. Morales, E. Borda, J.F. Perez, C. Pineiro and C. Chetrit, 2007. Dietary nucleotide supplementation reduces occurrence of diarrhoea in early weaned pigs. Livest. Sci., 108: 276-279.

Musa, H.H., S.L. Wu, C.H. Zhu, H.I. Seri and G.Q. Zhu, 2009. The potential benefits of probiotics in animal production and health. J. Anim. Vet. Adv., 8: 313-321.

Muthuswamy, K., S. Gopalakrishnan, T.K. Ravi and P. Sivachidabaram, 2008. Biosurfactants: Properties, Commercial production and application. Curr. Sci., 94: 736-746.

Nakano, M.M., M.A. Marahiel and P. Zuber, 1988. Identification of a genetic locus required for biosynthesis of the lipopeptide antibiotic surfactin in Bacillus subtilis. J. Bacteriol., 170: 5662-5668.

Narva, M, M. Collin, C. Lamberg-Allardt, M. Karkkainen, T. Poussa, H. Vapaatalo and R. Korpela, 2004. Effects of long-term intervention with Lactobacillus helveticus-fermented milk on bone mineral density and bone mineral content in growing rats. Ann. Nutr. Metab., 48: 228-234.

Otto, E.R., M. Yokoyama, S. Hengemuehle, R.D. Von Bermuth, T. van Kempen and N.L. Trottier, 2003. Ammonia, volatile fatty acids, phenolics and odor offensiveness in manure from growing pigs fed diets reduced in protein concentration. J. Anim. Sci., 81: 1754-1763.

Parvez, S., K.A. Malik, S.A. Kang and H.Y. Kim, 2006. Probiotics and their fermented food products are beneficial for health. J. Applied Microbiol., 100: 1171-1185. 
Polin, D., 1980. Increased absorption of tallow with lecithin. Poult. Sci., 59: 1652-1652.

Prasad, J., H. Gill, J. Smart and P.K. Gopal, 1998. Selection and characterization of Lactobacillus and Bifidobacterium strains for use as probiotics. Int. Dairy J., 8: 993-1002.

Priest, F.G., 1977. Extracellular enzyme synthesis in the genus Bacillus. Bacteriol. Rev., 41: 711-753.

Priest, F.G., 1989. Isolation and Identification of Aerobic Endospores Forming Bacteria. In: Bacillus, Harwood, C.R. (Ed.). Vol. 2, Plenum Press, New York, ISBN: 9780306431371, pp: 27-56.

Sherman, P.M., K.C. Johnson-Henry, H.P. Yeung, P.S.C. Ngo, J. Goulet and T.A. Tompkins, 2005. Probiotics reduce enterohemorrhagic Escherichia coli $\mathrm{O} 157: \mathrm{H} 7$ - and enteropathogenic E. coli $\mathrm{O} 127$ : H6-induced changes in polarized T84 epithelial cell monolayers by reducing bacterial adhesion and cytoskeletal rearrangements. Infect. Immun., 73: $5183-5188$.
Smith, T.J. and S.J. Foster, 1995. Characterization of the involvement of two compensatory autolysins in mother cell lysis during sporulation of Bacillus subtilis 168. J. Bacteriol., 177: 3855-3862.

Soares, M. and C.J. Lopez-Bote, 2002. Effects of dietary lecithin and fat unsaturation on nutrient utilisation in weaned piglets. Anim. Feed Sci. Technol., 95: 169-177.

Tam, N.K.M., N.Q. Uyen, H.A. Hong, L.H. Duc and T.T. Hoa et al., 2006. The intestinal life cycle of Bacillus subtilis and close relatives. J. Bacteriol., 188: 2692-2700.

Thompson, J.K., M.A. Collins and W.D. Mercer, 2008. Characterization of a proteinaceous antimicrobial produced by Lactobacillus helveticus CNRZ450. J. Applied Microbiol., 80: 338-348.

Watson, A.A., G.W.J. Fleet, N. Asano, R.J. Molyneux and R.J. Nash, 2001. Polyhydroxylated alkaloids-natural occurrence and therapeutic applications. Phytochemistry, 56: 265-295.

Whalon, M.E. and B.A. Wingerd, 2003. Bt: Mode of action and use. Arch. Insect Biochem. Physiol., 54: 200-211. 